Research Article

\title{
Development of Evaluation Index Model for Activation and Promotion of Public Space in the Historic District Based on AHP/DEA
}

\author{
Fengwen Wu $\mathbb{D}^{1},{ }^{1}$ Shiyu Qin, ${ }^{2}$ Chunyu Su, ${ }^{1}$ Mingyuan Chen, ${ }^{1}$ Qian Wang, ${ }^{3}$ and Qizeng Zhang ${ }^{1}$ \\ ${ }^{1}$ Institute of Urban Design, Beijing University of Technology, Beijing 100124, China \\ ${ }^{2}$ IBartlett School of Architecture, University College London, London, UK \\ ${ }^{3}$ Beijing Historical Building Protection Engineering Technology Research Center, Beijing University of Technology, \\ Beijing 100124, China \\ Correspondence should be addressed to Fengwen Wu; wufengwen123@126.com
}

Received 24 May 2021; Accepted 3 November 2021; Published 11 December 2021

Academic Editor: David Bigaud

Copyright (c) 2021 Fengwen Wu et al. This is an open access article distributed under the Creative Commons Attribution License, which permits unrestricted use, distribution, and reproduction in any medium, provided the original work is properly cited.

\begin{abstract}
Historic districts represent an important characteristic of Beijing and are also a crucial carrier of Chinese historic culture. However, they are significantly affected by the rapid urban constructions. Thus, it is of great significance to maintain and promote the public space in historic districts. This paper uses a multisource data superposition method to select the evaluation index of public space. The AHP was also used to complete the single-level and total-level ranking and calculation of evaluation indexes. Finally, based on the DEA model, a vitality evaluation model of Beijing historic district public spaces was developed and its validity was verified through a case study of the Wanping historic district.
\end{abstract}

\section{Introduction}

Public space of historic districts puts an important imprint on Beijing city. It includes living space, landscape, and historical buildings built in different historical periods. Additionally, public space of historic districts is the carrier of Chinese histories and cultures in Beijing. That is, it has the historical and cultural characteristics of the city. However, the rapid development of urban construction has affected the vitality of the public space in historic districts. Thus, there is a need to improve and maintain the vitality of public space.

Nevertheless, the promotion of the public space in historic districts is a continuous process, and it is important to maintain the historical and cultural characters to highlight the unique characteristics of individual regions and maintain the overall vitality of the public space in historic districts. This requires a continuous joint effect from every party in the society.
In addition, the planning and construction of the public space in Beijing's historic districts should also keep pace with the times. This paper uses quantitative data analysis and applies the big data analysis of the AHP/DEA model to study the public space in historic districts. This paper aims to develop a more efficient and effective scientific method to promote the public space of historic districts. Using AHP and DEA models to analyze the big data, this paper also constructs and verifies the validity of an index evaluation system of the public space vitality utilization in historic districts.

\section{Literature Review}

2.1. Studies Conducted in China and Overseas. Currently, there are many studies conducted in China and overseas, in the areas of concept, theory, design, and practice. The concept of "sustainable development" is promoted in the protection of historic districts internationally. Many 
researchers have been working on the protection of cultural heritage and the development of historic districts theories.

The researchers used the "Google Academic" search engine and found a total of 24900 results of "historic district" using multidirectional and multiangle protection methods. These studies used multidirectional and multiangle protection methods, and the researchers categorized them into the following main categories: (1) building protection, (2) urban protection, (3) urban economics, (4) spatial perception, (5) culture promotion, (6) community planning, (7) ecological city, and (8) spatial syntax.

For example, Yisan Ruan [1] from Tongji University found that we should pay attention to the "authenticity, integrity, readability, and sustainability" of the historic districts and follow the idea of "renovating the old as before, so as to preserve its truth" to protect traditional buildings. Many other scholars, such as Wang Jing hui and Wang Lin [2] have also provided detailed suggestions on the reconstruction of Chinese historic districts for the protection and further study of urban culture.

2.2. Public Space in Historic Districts. Researchers of this paper searched the keyword "public space" in "Google Academic" and found a total of 681000 results initially. However, when researchers searched the key word "the public space of historic districts," only a few studies were found. Thus, it was noted "the public space" has been studied by many researchers, while limited research has been conducted on "historic districts." The researchers also used Pro Quest dissertation full-text search platform and found that this keyword was not involved in any dissertation. Only the two most relevant articles were located, and they can be categorized into urban diversification and cultural renaissance [3] for reference.

In China, little attention was paid to the public space of historic and cultural districts. With the increasing urban development, more attention should be paid to the development and maintenance of public spaces in historic districts blocks.

The research results from 2005 to the end of 2020 of CNKI show that there are more studies conducted on the public space of historic districts. Six-hundred twenty results were found when the keyword "public space of historical block" were searched in CNKI. Ninety-four related documents were selected, including 30 journal papers, 56 master's papers, two doctoral papers, and six conference papers. A comparative analysis of the publication trend of the selected references was conducted and found that the research on the public space of the historic districts has been increased yearly, but the growth momentum is not decreased. The majority of the research results are mainly coming from master's theses (60\%), and only $2 \%$ are from doctoral research. It shows further in-depth academic research is needed in the area of public space in historic districts.

\subsection{Review on the Vitality of Public Space in Historic Districts.} Since early 20th century, urban developers have been exploring how to organize urban public space and study the impact of space on urban development overseas. This process emphasizes the concept of space vitality, and thus, a series of theoretical research was conducted to study space vitality and the ways of space activation [4].

The study shows the results of research conducted on "public space of historic districts." This paper divides the research categories into evaluation system, cultural construction, space quality, space transformation, and diversified design and construction [5].

The concept of space vitality has been explored theoretically by many researchers. Currently, China also starts to study the importance of space vitality. However, it was found there are few studies on the public space of historic districts. Therefore, this current study found 298,000 results while searching "public space vitality" as the keyword in the "Google Academic" engine, and this paper analyzes the relevant literature from the aspects of urban economics, public space vitality, post-humanism, space management, urban sociology, space quality, and space transformation.

The research on the public space in historic and cultural districts in China has gradually changed from material level to nonmaterial level, from focusing on the renovation of the space environment to the quality and culture of space. Meanwhile, some researchers such as Fengwen Wu [6], Xinjian Li [7], and Ping Ju [8] tried to develop the evaluation system of public space in historic districts and studied the various aspects of the public space by using spatial evaluation. However, the evaluation research of public space was not theorized currently, and the evaluation method is mostly developed based on subjective analysis. Moreover, only the PSPL method [9] has been used to develop the quality index, and it lacks certain objectivity and authenticity. Therefore, further study in the evaluation mode is needed to study public space in historic districts further.

There is much research undertaken on the vitality of public space in historic districts in China and overseas, and they shared some common characteristics. For example, they used similar developing procedures. They all start from the overall urban space and gradually turn to the activation of public space in historic districts [10]. In China, further research on the vitality of public space in historic districts has been done to the level of material elements, and the influence of social and cultural attributes on the vitality of space has been focused. Moreover, the construction of the space vitality evaluation system and big data for vitality quantitative research has gradually become a popular area to work. Much research has been using quantitative analysis and evaluation in China $[11,12]$, and most of them is focusing on the factors that are affecting the vitality. There is a lack of practical judgment of spatial vitality. Thus, this paper is to explore this area further.

\section{Study of Methods}

3.1. The Principles of AHP. Analytic Hierarchy Process (AHP) is a multicriteria and multilevel decision-making analysis method which uses experts' judgment and transforms qualitative data into quantitative data. This method has been used for the determination of important weights of 
the lowest level (scheme, measure, etc.) to the highest level (overall goal based on their significant values) [13].

This paper used AHP to calculate the index weight. The specific steps are as follows.

In order to ensure the validity and reliability of the research, this paper adopted the judgment method of pairwise comparison to establish the matrix for the first- and second-level indicators. It was then inputted into MATLAB software to calculate the eigenvalue. Finally, it obtained the eigenvector as the index weight value of the evaluation system, obtained the ratio, and formed multiple n-order judgment matrices.

Step 1. Construct the judgment matrix, as shown in

$$
A=\left(a_{i j}\right)_{n n^{\prime}} \quad(i, j=1,2, \ldots, n) .
$$

Step 2. Calculate the eigenvalues and eigenvectors.

After the judgment matrix is constructed, the maximum eigenvalue of each judgment matrix $\lambda_{\max }$ and its corresponding eigenvector $W_{i}$ are calculated, respectively, as shown in

$$
\begin{aligned}
\lambda_{\max } & =\sum_{i=1}^{n}\left(\frac{(A W)_{i}}{n W_{i}}\right), \quad(i=1,2, \ldots, n), \\
W_{i} & =\sqrt[n]{\frac{\prod_{j=1}^{n} a_{i j}}{\sum_{i=1}^{n} \sqrt[n]{\prod_{j=1}^{n} a_{i j} .}}}
\end{aligned}
$$

Step 3. Conduct the consistency test.

The matrix needs to be reconstructed until it passes the consistency test. $n$ is the order of the judgment matrix and $C_{I}$ is the consistency indicator of the judgment matrix, as shown in formula (4). $R_{I}$ is the random consistency indicator and $C_{R}$ is the consistency ratio, as shown in formula (5). When $C_{R}<0.1$, the consistency test is passed. The value of the average random consistency indicator is determined by the literature [14] (see Table 1):

$$
\begin{aligned}
C_{I} & =\frac{\lambda_{\max }-n}{n-1}, \\
C_{R} & =\frac{C_{I}}{R_{I}} .
\end{aligned}
$$

Step 4. Calculate the combined weights.

The combined weight vector of each indicator for the target layer is shown in

$$
w_{i}^{\prime}=W^{r} W^{r-1}, \ldots, W^{3} w_{i}^{2}
$$

where $w_{i}^{\prime}$ is the weight of each indicator, $w_{i}^{\prime} \geq 0$ and $\sum w_{i}^{\prime}=1$, and $r$ is the number of layers of the index system.

3.2. DEA Model. Data Envelopment Analysis (DEA) was used to compare the efficiency of multiple service units providing similar services by explicitly considering the use of
TABLE 1: Value of average random consistency indicator $R_{I}$.

\begin{tabular}{cccccccccc}
\hline$n$ & 1 & 2 & 3 & 4 & 5 & 6 & 7 & 8 & 9 \\
\hline$R_{I}$ & 0 & 0 & 0.52 & 0.89 & 1.12 & 1.26 & 1.36 & 1.41 & 1.46 \\
\hline
\end{tabular}

multiple inputs (i.e., resources) and the generation of multiple outputs (i.e., services). It avoided calculating the standard cost of each service unit, because it converted multiple inputs and outputs into the numerator and denominator of efficiency ratio, rather than using the same monetary unit. Therefore, DEA was used to explain the combination of input and output to measure efficiency. It was more comprehensive and reliable than a set of operating ratios or profit indexes [15].

DEA is also a linear programming model, for the ratio of output to input. It compares the efficiency of a specific unit with the performance of a group of similar units, which provides similar services. It also tries to maximize the efficiency of the service unit. Through this process, some units with $100 \%$ efficiency were called relative efficiency units, while others with efficiency scores lower than $100 \%$ were called inefficiency units [11].

Enterprise managers have used DEA to compare groups of service units, identify relative inefficiency units, measure the severity of inefficiency, and find ways to reduce inefficiency by comparing inefficiency and efficiency units.

3.2.1. Analysis of DEA model results. The most commonly used mathematical model of DEA is the CCR model with constant returns to scale, to calculate technical efficiency. The BCC model can also be used with variable returns to scale, to calculate pure technical efficiency.

3.3. CCR Model. Suppose there are $n$ DMUs in the decision system, and each DMU has $m$ inputs and $R$ outputs. The $j$-th decision unit is named DMUj $(1 \leq J \leq n)$ (see Table 2$)$.

$X_{j}$ is the input quantity of the $j$ of DMU and $Y_{j}$ is the output quantity, which is recorded as follows: $X_{j}=\left(x_{j}^{1}, x_{j}^{2}, \ldots, x_{j}^{m} m j\right) T, Y_{j}=\left(y_{j}^{1}, y_{j}^{2}, \ldots, y_{j}^{r}\right) T, \quad v=\left(v_{1}\right.$, $\left.v_{2}, \ldots, v_{m}\right) T$, and $u=\left(u_{1}, u_{2}, \ldots, u_{r}\right) T, 1 \leq j \leq n$.

The efficiency evaluation index of the $j$-th decisionmaking unit is shown in

$$
h_{j}=\frac{u^{T} Y_{j}}{v^{T} X_{j}}, \quad 1 \leq j<n,
$$

where $x_{0}=x_{0}^{i}, y_{0}=y_{0}^{i}, 1 \leq i_{0} \leq n$, and $h_{i}=u^{T} Y_{i} / v^{T} X_{i} \leq 1, i=$ $1,2, \leftrightharpoons$, and $n$ is the constraint to construct the model, as shown in the following equation with $\max u^{T} y_{0} / v^{T} x_{0}$ :

$$
\text { s.t. } \frac{u^{T} Y_{j}}{v^{T} X_{j}} \leq 1, \quad i=1,2, \rightleftharpoons, n, u \geq 0, v \geq 0
$$

In this model, $t=1 / v^{T} x_{0}, w=t v$, and $\mu=t u$, and an equivalent linear programming model can be obtained, as shown in the following formula with $\max u^{T} y_{0}$ : 
TABLE 2: Input-output system of DMU.

\begin{tabular}{ccccccccccc}
\hline & & & 1 & 2 & $\ldots$ & $j$ & $\ldots$ & $\mathrm{n}$ & \\
$v_{1}$ & 1 & $\longrightarrow$ & $x_{11}$ & $x_{12}$ & $\ldots$ & $x_{1 j}$ & $\ldots$ & $x_{1 n}$ & \\
$v_{2}$ & 2 & $\longrightarrow$ & $x_{21}$ & $x_{22}$ & $\ldots$ & $x_{2 j}$ & $\ldots$ & $x_{2 n}$ & \\
$\ldots$ & $\ldots$ & $\ldots$ & $\ldots$ & $\ldots$ & & $\ldots$ & & $\ldots$ & \\
$v_{m}$ & $m$ & $\longrightarrow$ & $x_{m 1}$ & $x_{m 2}$ & $\ldots$ & $x_{m j}$ & $\ldots$ & $x_{m n}$ & & \\
& & & & & & & & & & \\
& $u_{1}$ & $y_{11}$ & $y_{12}$ & $\ldots$ & $y_{1 j}$ & $\ldots$ & $x_{1 n}$ & $\longrightarrow$ & 1 \\
& $u_{2}$ & $y_{21}$ & $y_{22}$ & $\ldots$ & $y_{2 j}$ & $\ldots$ & $y_{2 n}$ & $\longrightarrow$ & 2 \\
& $\ldots$ & $\ldots$ & $\ldots$ & & $\ldots$ & & $\ldots$ & $\ldots$ & $\ldots$ \\
& $u_{r}$ & $y_{r 1}$ & $y_{r 2}$ & $\ldots$ & $y_{r j}$ & $\ldots$ & $y_{r n}$ & $\longrightarrow$ & $r$ \\
\hline
\end{tabular}

Note: $m$ is input, $r$ is output, $x_{j}$ is the input quantity of the $j$ of DMU, $y_{j}$ is the output quantity, $x_{j}=\left(x_{1 j}, x_{2 j} \ldots, x_{m j}\right) T, y_{j}=\left(y_{1 j}, y_{2 j} \ldots, y_{r j}\right) T . U_{j}$ is the size of management efficiency, $V_{j}$ is the statistical noise assessment value for each producer, $u=\left(u_{1}, u_{2} \cdots, u r\right) T, v=\left(v_{1}, v_{2} \cdots, v m\right) T, 1 \leq j \leq n$.

$$
\begin{aligned}
& \text { s.t. } \omega^{T} x_{i}-\mu^{T} y_{i} \geq 0, \quad i=1,2, \rightleftharpoons, n, \\
& \omega^{T} x_{0}=1, \\
& \omega \geq 0, \mu \geq 0 .
\end{aligned}
$$

The duality model of the above formula is established, and $s+$ and $s-$ are introduced. Here, $s+$ is the residual variable, $s^{+}=\left(s_{1}^{+}, s_{2}^{+}, \rightleftharpoons, s_{r}^{+}\right)^{T}, s^{-}$is a relaxation variable, $s^{-}=\left(s_{1}^{-}\right.$, $\left.s_{2}^{-}, \rightleftharpoons, s_{m}^{-}\right)^{T}$ (formula (10) for the dual form): with $\min \theta$,

$$
\begin{aligned}
& \text { s.t. } \sum_{i=1}^{n} \lambda_{i} x_{i}+s^{-}=\theta x_{0}, \\
& \sum_{i=1}^{n} \lambda_{i} y_{i}-s^{+}=y_{0}, \\
& \lambda_{i} \geq 0, i=1,2, \rightleftharpoons, n, \\
& s^{+} \geq 0, s^{-} \geq 0 .
\end{aligned}
$$

3.4. BCC Model. The BCC model does not consider the impact of returns to scale on technical efficiency and obtains pure technical efficiency. The model is shown in

$$
\begin{aligned}
& \min \left[\theta-\varepsilon\left(e^{T} s^{-}+e^{T} s^{-}\right)\right], \\
& \text {s.t. } Y \lambda-s^{+}=y_{0}, \\
& X \lambda+s^{-}=\theta x_{0} \\
& m l^{T} \lambda=1 \\
& \lambda \geq 0 \\
& s^{+} \geq 0, s^{-} \geq 0 .
\end{aligned}
$$

Here, $\quad e^{T}=(1,1, \rightleftharpoons, 1)^{T} \in E_{N}, e^{T}=(1,1, \rightleftharpoons, 1)^{T} \in E_{M}$, $m_{1}$ is $m \times 1$ unit vector, and $\lambda$ is $m \times 1$ constant vector.

Using the above linear models $\theta, \lambda, s+$, and $s^{-}$, the results can be divided into four categories.

When $\theta=1$ and $s^{+}=s^{-}=0$, the decision-making unit is effective, the technology is effective, and the scale is effective, and the input-output reaches the best scale.

When $\theta=1 s^{+} \neq 0$, and $s^{-} \neq 0$, the DMU is weakly DEA efficient. When $\theta<1$, the DMU is not DEA efficient.

\section{Construction of the Vitality Index System of Public Space in Historic Districts}

Using the human-oriented basis of multisource data superposition [13], this paper reviewed the literature, analyzed the network data, and used traditional research methods to have the superposition results of three-level indicators from the material and spiritual perspectives (see Table 3). AHP was used to divide the quantitative data into three levels: target level, criterion level, and indicator level. The target level was to enhance the vitality of public space with historical value. The criteria level and index level have been summarized in Table 3.

Table 4 shows that this paper put six first-class indicators into use, summarized 48 evaluation index elements (secondclass indicators), and summarized them into six evaluation criteria (first-class indicators), including spatial location conditions, spatial traffic environment, spatial quality, spatial historical atmosphere, spatial landscape design, and spatial operation control. The secondary indicators had different influences on the primary indicators, according to the investigation and analysis results. When the influence of some secondary indicators on the primary indicators was too low, the lower influence of the secondary indicators had a negative impact on the evaluation results of the whole index system. Moreover, too many indicators led to too complex AHP calculation process and more errors. Consequently, it impacted the final evaluation results of the vitality and efficiency of the public space in historic districts [16].

\section{Establishment of Input Indicators}

5.1. Screening Basis of the Input Index. In this paper, via summing up the vitality and efficiency indicators superimposed by multisource data, all the secondary indicators had a greater weight than the primary indicators and the evaluation indicators had a certain generalization level. The specific criteria for selecting indicators have been developed to "clean" the indicator data in Table 5 via questionnaire survey and expert evaluation.

\subsection{Screening Results of Input Indicators}

5.2.1. Screening Design. This study invited 300 scholars and managers with master's degree or above, who had a major in urban and rural planning, architecture, landscape architecture, and other related disciplines. They were also engaged in the management of urban and rural planning, or with the designers and the managers of the communities in various historic districts. A questionnaire survey was conducted to screen the indicators. Two-hundred forty-six valid surveys were collected, accounting for $82 \%$ of the total number. The second-level indicators with the voting rate less than $50 \%$ under each first-level indicator were selected as the input indicators of activation and promotion evaluation in the subsequent DEA model calculation.

5.2.2. Analysis of Screening Results. It was found there were 26 indicators with the voting rate below $50 \%$. They were the node density of $\mathrm{C}_{4}, \mathrm{~B}_{2}$ space traffic environment of $\mathrm{B}_{1}$ space location condition of the evaluation criteria layer, the node density of $C_{6}$ road of $B_{2}$ space traffic environment of $B_{1}$ space location condition of the evaluation criteria layer, $\mathrm{C}_{8}$ 
TABLE 3: Vitality summary of the historic district.

\begin{tabular}{|c|c|c|}
\hline Target layer & Criterion layer & Index level \\
\hline \multirow{9}{*}{ Material demand } & Public space & $\begin{array}{c}\text { Spatial arrangement } \\
\text { Spatial scale } \\
\text { Special interface } \\
\text { Greening species }\end{array}$ \\
\hline & \multirow{3}{*}{ Green landscape } & Green color \\
\hline & & Green level \\
\hline & & Commercial activities \\
\hline & \multirow{3}{*}{ Public service facilities } & Commercial layout \\
\hline & & Gathering place \\
\hline & & The utilization rate of historical buildings \\
\hline & \multirow{2}{*}{ Historical building } & Historical building layout \\
\hline & & Historic architectural style color \\
\hline \multirow{8}{*}{ Spiritual needs } & \multirow{5}{*}{ Historic culture } & Beijing culture \\
\hline & & Archway culture \\
\hline & & Religious culture \\
\hline & & Opera culture \\
\hline & & Happiness \\
\hline & \multirow{3}{*}{ User perception } & Comfortable sensation \\
\hline & & Satisfaction \\
\hline & & Thermal degree \\
\hline
\end{tabular}

identification system, $\mathrm{C}_{9}$ traffic station density, $\mathrm{C}_{10}$ surrounding road grade, $\mathrm{C}_{12}$ intelligent transportation service level, $\mathrm{C}_{13}$ walking safety, $\mathrm{C}_{15}$ parking capacity, $\mathrm{C}_{16}$ space trafficability; $\mathrm{B}_{3}$ space quality evaluation criteria layer includes $\mathrm{C}_{20}$ building details and decoration process quality, $\mathrm{C}_{21} \mathrm{D} / \mathrm{h}, \mathrm{C}_{22}$ development intensity, $\mathrm{C}_{23}$ underground space development depth, $\mathrm{C}_{24}$ ground pavement effect, and $\mathrm{C}_{25}$ environmental sanitation facilities.

In the evaluation index layer of $\mathrm{B}_{4}$ space historical atmosphere criterion layer, there were two indexes that did not meet the $50 \%$ vote rate, namely, $C_{27}$ space historic and $C_{30}$ historical event correlation. In the evaluation index layer of B5 space landscape design evaluation criteria layer, there were six indexes that did not exceed $50 \%$ of the voting rate, including $\mathrm{C}_{31}$ plant number, $\mathrm{C}_{32}$ plant species richness, $\mathrm{C}_{37}$ plant collocation, $\mathrm{C}_{35}$ green space coverage, $\mathrm{C}_{38}$ barrier-free facilities, and $\mathrm{C}_{41}$ identification facilities. These indexes had limited impact on the vitality of public space. In the evaluation criteria layer of $B_{6}$ space operation management and control, there were two indexes that did not have more than $50 \%$ of the votes, including the income of $\mathrm{C}_{43}$ industry and the security of $\mathrm{C}_{48}$ space, indicating that these indexes had little impact on the vitality of public space. It was found the 22 effective indexes of the 48 were obtained and the other 26 were removed. Table 5 shows the 26 input indexes and the description layers have little impact on the vitality of public space.

According to Table 6, the input indicators and their evaluation indicators are as follows.

In Table $6, B_{i}(I=1,2, \ldots, 6)$ of the first-level evaluation criteria were divided into six indicators:

(1) Spatial location condition [17] was the basic condition. Its resources for the activation and promotion of public space included three important measurement factors: spatial location, resources around the space, and spatial positioning and characteristics.

(2) Space traffic environment [18] was the key to the activation of public space to improve the use efficiency and was composed of four factors: road network density, traffic mode, pedestrian traffic comfort, and pedestrian street scale.

(3) The space quality [19] included the quality of the public space itself, the surrounding buildings, structures, squares, greening, and sketch facilities.

(4) The historical characteristics of public space [20] were composed of the fusion degree of ancient and modern styles, the preservation degree of historical buildings and environment, and the identification degree of historical texture. These indicators were also important to the vitality and efficiency of public space.

(5) Space landscape design [21, 22] determined the quality of public space and included five factors: plant color richness, water landscape design, shading rate, lighting facilities, and recreation facilities.

(6) Space operation management [23] was key to the longterm vitality of public space, and it was studied from five perspectives. The density was the ratio of this service formats to all. The organization management was measured by policy terms. The cleanliness and maintenance of space facilities reflected the management and control effect of public space operation.

In summary, based on the characteristics of the input and output of the vitality promotion of the public space in the historic district, this paper investigated the qualitative and quantitative factors. The factors were comprehensively studied in the investment of the vitality promotion, and a two-stage 
TABLE 4: Vitality summary of public space of historic districts.

\begin{tabular}{|c|c|}
\hline Evaluation criterion layer, $B_{i}(i=1,2, \ldots, 6)$ & Evaluation index layer, $C_{i}(i=1,2, \ldots, 48)$ \\
\hline $\mathrm{B}_{1}$ spatial location condition & $\begin{array}{c}\mathrm{C}_{1} \text { spatial location } \\
\mathrm{C}_{2} \text { space peripheral resources } \\
\mathrm{C}_{3} \text { spatial orientation and characteristics } \\
\mathrm{C}_{4} \text { landscape overall spatial pattern }\end{array}$ \\
\hline $\mathrm{B}_{2}$ space traffic environment & $\begin{array}{c}\mathrm{C}_{5} \text { road network density } \\
\mathrm{C}_{6} \text { road node density } \\
\mathrm{C}_{7} \text { means of transportation } \\
\mathrm{C}_{8} \text { tag system } \\
\mathrm{C}_{9} \text { traffic stop density } \\
\mathrm{C}_{10} \text { peripheral road grade } \\
\mathrm{C}_{11} \text { comfort of pedestrian traffic } \\
\mathrm{C}_{12} \text { intelligent traffic service level } \\
\mathrm{C}_{13} \text { walking safety } \\
\mathrm{C}_{14} \text { pedestrian street scale } \\
\mathrm{C}_{15} \text { parking capacity } \\
\mathrm{C}_{16} \text { spatial traversability }\end{array}$ \\
\hline
\end{tabular}

$\mathrm{C}_{17}$ architectural features

$\mathrm{C}_{18}$ permeability of building interface

$\mathrm{C}_{19}$ building space form and scale

$\begin{array}{cc}\mathrm{B}_{3} \text { space quality } & \mathrm{C}_{21} \mathrm{~d} / \mathrm{h} \\ \mathrm{C}_{22} \text { development intensity }\end{array}$

$\mathrm{C}_{20}$ construction details and decoration process quality

$\mathrm{C}_{23}$ development depth of underground space

$\mathrm{C}_{24}$ ground pavement effect

$\mathrm{C}_{25}$ environment sanitation facilities

$\mathrm{C}_{26}$ fusion of ancient and modern styles

$\mathrm{C}_{27}$ spatial reality

$\mathrm{B}_{4}$ space historical atmosphere

$\mathrm{C}_{28}$ retention degree of historical buildings and historical environment

$\mathrm{C}_{29}$ historical texture recognition

$\mathrm{C}_{30}$ relevance of historical events

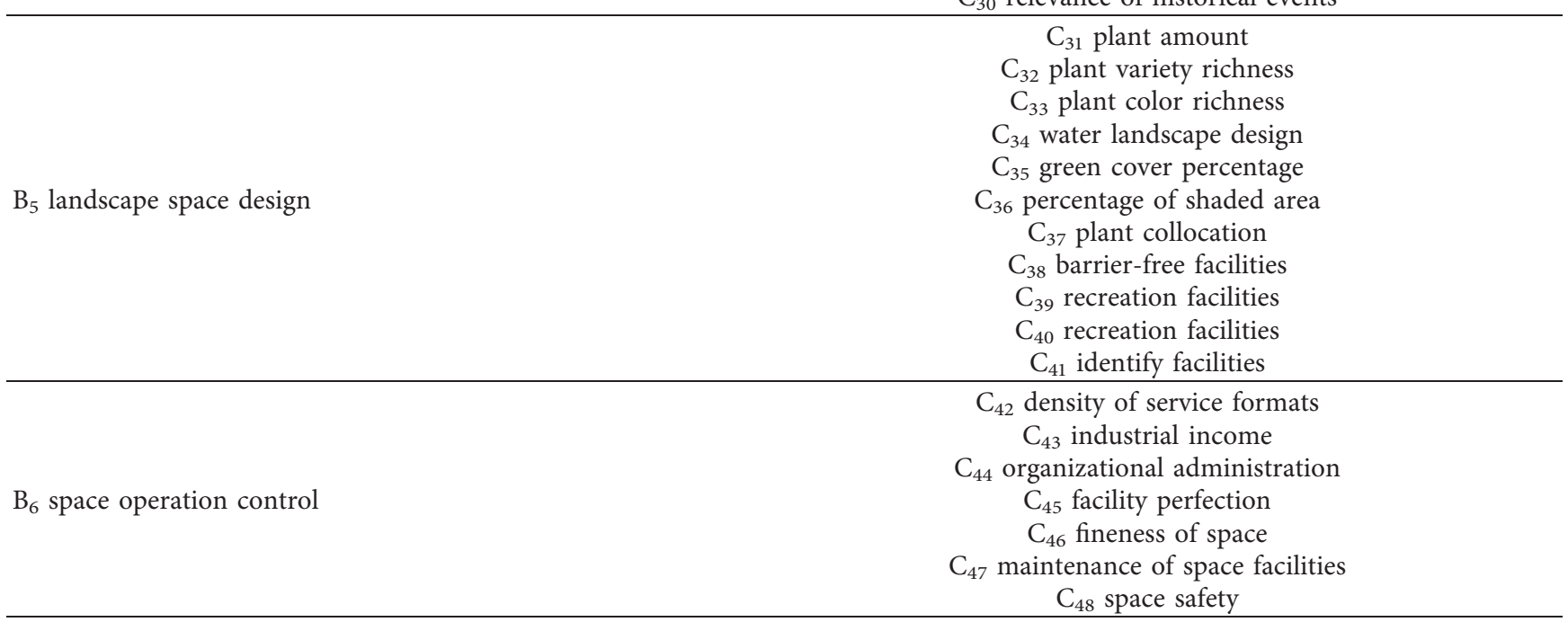

evaluation model combining AHP and DEA models was established. The first stage was the AHP analysis, in which the qualitative factors such as spatial location conditions, spatial traffic environment, spatial quality, spatial historical atmosphere, spatial landscape design, and spatial operation control were investigated, and the analysis results were used as an input index of the DEA model. The second stage was DEA model evaluation. The DEA model focused on the analysis of quantitative factors (see Table 7). The CCR and BCC models were used to evaluate the vitality input-output efficiency of the selected public space in the historic districts. Moreover, the evaluation results were analyzed as well.

\section{Results and Discussion}

6.1. Case Study. The case study was based in Wanping historic district (see Figure 1). It is a city with a total area of about 120 hectares. It reaches Yongding River in the west, 
TABLE 5: Results of survey data on the vitality of public space in historic districts.

\begin{tabular}{|c|c|c|c|c|}
\hline Evaluation criteria, $B_{i}(i=1,2, \ldots, 6)$ & Evaluation index layer, $C_{i}(i=1,2, \ldots, 48)$ & Votes & Total & Percentages \\
\hline \multirow{4}{*}{$\mathrm{B}_{1}$ spatial location condition } & $\mathrm{C}_{1}$ spatial location & 204 & 246 & 82.93 \\
\hline & $\mathrm{C}_{2}$ space peripheral resources & 189 & 246 & 76.83 \\
\hline & $\mathrm{C}_{3}$ spatial orientation and characteristics & 171 & 246 & 69.51 \\
\hline & $\mathrm{C}_{4}$ landscape overall spatial pattern & 69 & 246 & 28.05 \\
\hline \multirow{12}{*}{$\mathrm{B}_{2}$ space traffic environment } & $\mathrm{C}_{5}$ road network density & 202 & 246 & 82.11 \\
\hline & $\mathrm{C}_{6}$ road node density & 72 & 246 & 29.27 \\
\hline & $\mathrm{C}_{7}$ means of transportation & 198 & 246 & 80.49 \\
\hline & $\mathrm{C}_{8}$ tag system & 71 & 246 & 28.86 \\
\hline & $\mathrm{C}_{9}$ traffic stop density & 67 & 246 & 27.24 \\
\hline & $\mathrm{C}_{10}$ peripheral road grade & 115 & 246 & 46.71 \\
\hline & $\mathrm{C}_{11}$ comfort of pedestrian traffic & 223 & 246 & 90.65 \\
\hline & $\mathrm{C}_{12}$ intelligent traffic service level & 89 & 246 & 36.18 \\
\hline & $\mathrm{C}_{13}$ walking safety & 83 & 246 & 33.74 \\
\hline & $\mathrm{C}_{14}$ pedestrian street scale & 234 & 246 & 95.12 \\
\hline & $\mathrm{C}_{15}$ parking capacity & 87 & 246 & 35.36 \\
\hline & $\mathrm{C}_{16}$ spatial traversability & 89 & 246 & 37.4 \\
\hline \multirow{9}{*}{$\mathrm{B}_{3}$ space quality } & $\mathrm{C}_{17}$ architectural features & 176 & 246 & 71.54 \\
\hline & $\mathrm{C}_{18}$ permeability of building interface & 168 & 246 & 68.29 \\
\hline & $\mathrm{C}_{19}$ building space form and scale & 159 & 246 & 64.63 \\
\hline & $\mathrm{C}_{20}$ construction details and decoration process quality & 48 & 246 & 19.51 \\
\hline & $\mathrm{C}_{21} D / h$ & 121 & 246 & 49.18 \\
\hline & $\mathrm{C}_{22}$ development intensity & 65 & 246 & 28.05 \\
\hline & $\mathrm{C}_{23}$ development depth of underground space & 76 & 246 & 30.89 \\
\hline & $\mathrm{C}_{24}$ ground pavement effect & 93 & 246 & 37.80 \\
\hline & $\mathrm{C}_{25}$ environment sanitation facilities & 109 & 246 & 44.30 \\
\hline \multirow{5}{*}{$\mathrm{B}_{4}$ space historical atmosphere } & $\mathrm{C}_{26}$ fusion of ancient and modern styles & 195 & 246 & 79.27 \\
\hline & $\mathrm{C}_{27}$ spatial reality & 74 & 246 & 30.08 \\
\hline & $\mathrm{C}_{28}$ retention degree of historical buildings and historical environment & 170 & 246 & 69.10 \\
\hline & $\mathrm{C}_{29}$ historical texture recognition & 198 & 246 & 80.49 \\
\hline & $\mathrm{C}_{30}$ relevance of historical events & 85 & 246 & 34.55 \\
\hline \multirow{11}{*}{$\mathrm{B}_{5}$ landscape space design } & $\mathrm{C}_{31}$ plant amount & 112 & 246 & 45.53 \\
\hline & $\mathrm{C}_{32}$ plant variety richness & 109 & 246 & 44.31 \\
\hline & $\mathrm{C}_{33}$ plant color richness & 175 & 246 & 71.14 \\
\hline & $\mathrm{C}_{34}$ water landscape design & 162 & 246 & 65.85 \\
\hline & $\mathrm{C}_{35}$ green cover percentage & 78 & 246 & 31.71 \\
\hline & $\mathrm{C}_{36}$ percentage of shaded area & 167 & 246 & 67.89 \\
\hline & $\mathrm{C}_{37}$ plant collocation & 87 & 246 & 35.37 \\
\hline & $\mathrm{C}_{38}$ barrier-free facilities & 89 & 246 & 36.18 \\
\hline & $\mathrm{C}_{39}$ recreation facilities & 223 & 246 & 90.65 \\
\hline & $\mathrm{C}_{40}$ recreation facilities & 205 & 246 & 83.33 \\
\hline & $\mathrm{C}_{41}$ identify facilities & 78 & 246 & 31.71 \\
\hline \multirow{7}{*}{$\mathrm{B}_{6}$ space operation control } & $\mathrm{C}_{42}$ density of service formats & 196 & 246 & 79.67 \\
\hline & $\mathrm{C}_{43}$ industrial income & 56 & 246 & 22.76 \\
\hline & $\mathrm{C}_{44}$ organizational administration & 196 & 246 & 79.67 \\
\hline & $\mathrm{C}_{45}$ facility perfection & 218 & 246 & 88.62 \\
\hline & $\mathrm{C}_{46}$ fineness of space & 204 & 246 & 82.93 \\
\hline & $\mathrm{C}_{47}$ maintenance of space facilities & 198 & 246 & 80.49 \\
\hline & $\mathrm{C}_{48}$ space safety & 101 & 246 & 41.06 \\
\hline
\end{tabular}

Beijing-Guangzhou Railway in the east and north, and Beijing-Shi Expressway in the south. It is a multicultural place. The interior of Wanping historic district is mainly used for tourism and museum exploration. There is a sculpture garden outside the city through the longitudinal axis and the Anti-Japanese War Memorial Hall. It has an important historical background about the July 7th Lugou Bridge Incident. It is also famous for Lugou Xiaoyue Ming History and Yongding Anning Pray for Peace. Many national activities and international activities have been undertaken in this city. It is also a popular venue for patriotism education and many public commemoration activities and leisure tourism [24].

6.2. Sample Data. The satisfaction level was a crucial indicator of historic district public space vitality $[25,26]$. This study used the relevant input indicators, Octopus software microblogging service data, and data from the present situation investigation and classified statistical evaluation of 
TABLE 6: Input of the votes of the evaluation index layer.

\begin{tabular}{|c|c|c|c|c|}
\hline Evaluation criteria, $B_{i}(i=1,2, \ldots, 6)$ & Evaluation index layer, $C_{i}(i=1,2, \ldots, 48)$ & Votes & Total & Percentages \\
\hline \multirow{3}{*}{$\mathrm{B}_{1}$ spatial location condition } & $\mathrm{C}_{1}$ spatial location & 20 & 24 & 82.93 \\
\hline & $\mathrm{C}_{2}$ space peripheral resources & 18 & 24 & 76.83 \\
\hline & $\mathrm{C}_{3}$ spatial orientation and characteristics & 17 & 24 & 69.51 \\
\hline \multirow{4}{*}{$\mathrm{B}_{2}$ space traffic environment } & $\mathrm{C}_{5}$ road network density & 20 & 24 & 82.11 \\
\hline & $\mathrm{C}_{7}$ means of transportation & 19 & 24 & 80.49 \\
\hline & $\mathrm{C}_{11}$ comfort of pedestrian traffic & 23 & 24 & 90.65 \\
\hline & $\mathrm{C}_{14}$ pedestrian street scale & 23 & 24 & 95.12 \\
\hline \multirow{3}{*}{$\mathrm{B}_{3}$ space quality } & $\mathrm{C}_{17}$ architectural features & 17 & 24 & 71.54 \\
\hline & $\mathrm{C}_{18}$ permeability of building interface & 16 & 24 & 68.29 \\
\hline & $\mathrm{C}_{19}$ building space form and scale & 15 & 24 & 64.63 \\
\hline \multirow{8}{*}{$\mathrm{B}_{4}$ space historical atmosphere } & $\mathrm{C}_{26}$ fusion of ancient and modern styles & 19 & 24 & 79.27 \\
\hline & $\mathrm{C}_{28}$ retention degree of historical buildings and historical environment & 17 & 24 & 69.10 \\
\hline & $\mathrm{C}_{29}$ historical texture recognition & 19 & 24 & 80.49 \\
\hline & $\mathrm{C}_{33}$ plant color richness & 17 & 24 & 71.14 \\
\hline & $\mathrm{C}_{34}$ water landscape design & 16 & 24 & 65.85 \\
\hline & $\mathrm{C}_{36}$ percentage of shaded area & 16 & 24 & 67.89 \\
\hline & $\mathrm{C}_{39}$ recreation facilities & 22 & 24 & 90.65 \\
\hline & $\mathrm{C}_{40}$ recreation facilities & 20 & 24 & 83.33 \\
\hline \multirow{6}{*}{$\mathrm{B}_{6}$ space operation control } & $\mathrm{C}_{42}$ density of service formats & 19 & 24 & 79.67 \\
\hline & $\mathrm{C}_{43}$ industrial income & 56 & 24 & 22.76 \\
\hline & $\mathrm{C}_{44}$ organizational administration & 19 & 24 & 79.67 \\
\hline & $\mathrm{C}_{45}$ facility perfection & 21 & 24 & 88.62 \\
\hline & $\mathrm{C}_{46}$ fineness of space & 20 & 24 & 82.93 \\
\hline & $\mathrm{C}_{47}$ maintenance of space facilities & 19 & 24 & 80.49 \\
\hline
\end{tabular}

TABLE 7: Inductive input indicators and their description layers.

\begin{tabular}{|c|c|}
\hline Evaluation criterion layer, $B_{i}(i=1,2, \ldots, 6)$ & Evaluation index layer, $C_{i}(i=1,2, \ldots, 48)$ \\
\hline $\mathrm{B}_{1}$ spatial location condition & $\begin{array}{c}\mathrm{C}_{1} \text { spatial location } \\
\mathrm{C}_{2} \text { space peripheral resources } \\
\mathrm{C}_{3} \text { spatial orientation and characteristics }\end{array}$ \\
\hline $\mathrm{B}_{2}$ space traffic environment & $\begin{array}{l}\mathrm{C}_{5} \text { density of road network } \\
\mathrm{C}_{7} \text { means of transportation } \\
\mathrm{C}_{11} \text { comfort of pedestrian traffic } \\
\mathrm{C}_{14} \text { pedestrian street scale }\end{array}$ \\
\hline $\mathrm{B}_{3}$ space quality & $\begin{array}{c}\mathrm{C}_{17} \text { architectural features } \\
\mathrm{C}_{18} \text { permeability of building interface } \\
\mathrm{C}_{19} \text { building space form and scale }\end{array}$ \\
\hline $\mathrm{B}_{4}$ Space historical atmosphere & $\begin{array}{c}\mathrm{C}_{26} \text { degree of integration of ancient and modern styles } \\
\mathrm{C}_{28} \text { retention degree of historical buildings and historical environment } \\
\mathrm{C}_{29} \text { historical texture recognition }\end{array}$ \\
\hline $\mathrm{B}_{5}$ landscape space design & $\begin{array}{c}\mathrm{C}_{33} \text { plant color richness } \\
\mathrm{C}_{34} \text { water landscape design } \\
\mathrm{C}_{36} \text { percentage of shaded area } \\
\mathrm{C}_{39} \text { lighting facility } \\
\mathrm{C}_{40} \text { recreation facilities }\end{array}$ \\
\hline $\mathrm{B}_{6}$ space operation control & $\begin{array}{c}\mathrm{C}_{42} \text { density of service formats } \\
\mathrm{C}_{44} \text { organizational administration } \\
\mathrm{C}_{45} \text { facility perfection } \\
\mathrm{C}_{46} \text { fineness of space } \\
\mathrm{C}_{47} \text { maintenance of space facilities }\end{array}$ \\
\hline
\end{tabular}




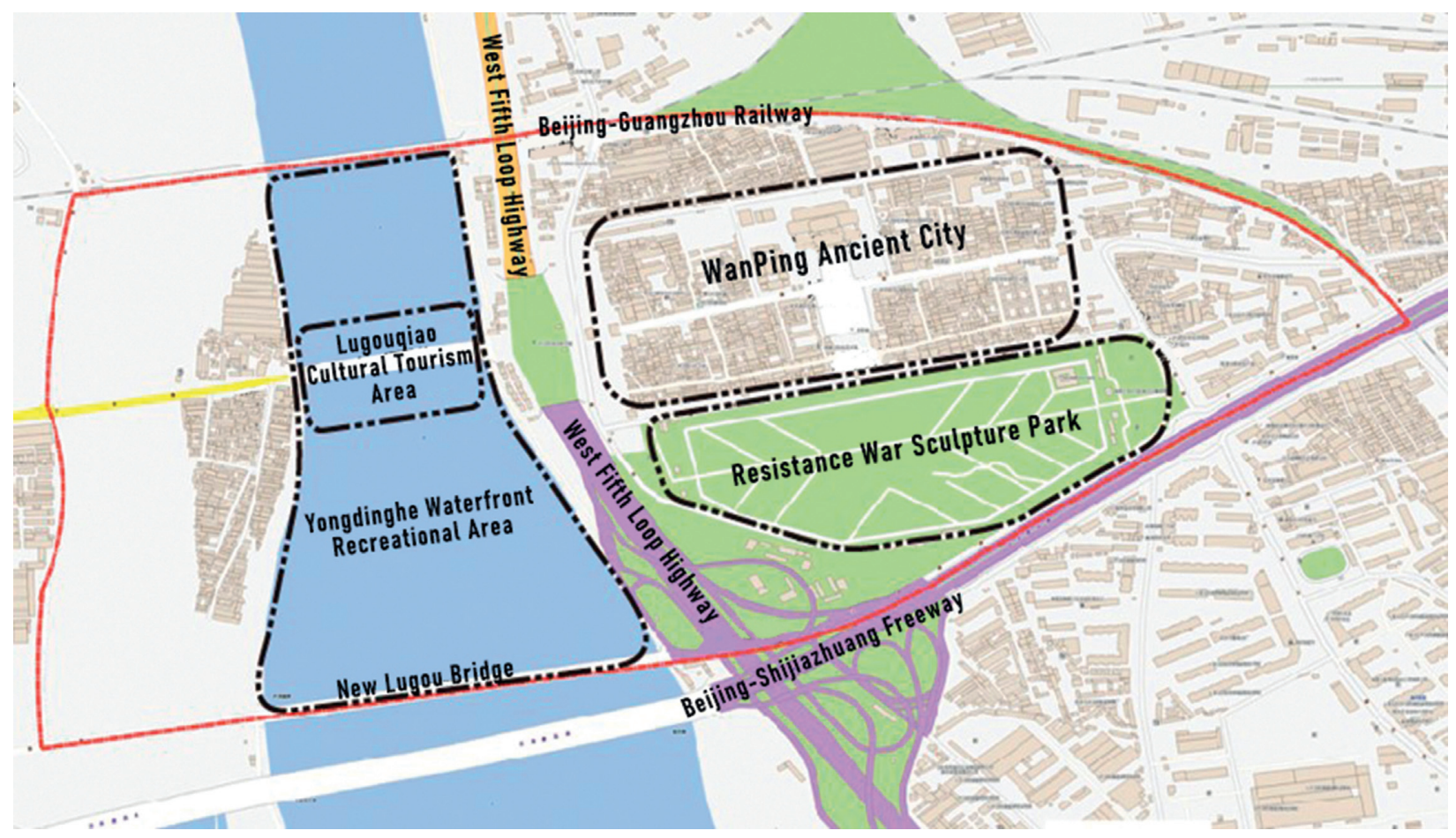

FIGURE 1: Site of the Wanping historic district.

TABLE 8: Historic district satisfaction analysis.

\begin{tabular}{|c|c|c|c|c|c|c|}
\hline $\begin{array}{l}\text { Decision- } \\
\text { making units }\end{array}$ & $\begin{array}{c}\mathrm{B}_{1} \text { spatial location } \\
\text { condition }\end{array}$ & $\begin{array}{c}\mathrm{B}_{2} \text { space traffic } \\
\text { environment }\end{array}$ & $\mathrm{B}_{3}$ space quality & $\begin{array}{c}\mathrm{B}_{4} \text { space historical } \\
\text { atmosphere }\end{array}$ & $\begin{array}{c}\mathrm{B}_{5} \text { landscape space } \\
\text { design }\end{array}$ & $\begin{array}{c}\mathrm{B}_{6} \text { space operation } \\
\text { control }\end{array}$ \\
\hline & $\begin{array}{c}\text { Total quantity } \\
\text { satisfaction } \\
\text { measure }\end{array}$ & $\begin{array}{l}\text { Total quantity } \\
\text { satisfaction } \\
\text { measure }\end{array}$ & $\begin{array}{l}\text { Total quantity } \\
\text { satisfaction } \\
\text { measure }\end{array}$ & $\begin{array}{c}\text { Total quantity } \\
\text { satisfaction } \\
\text { measure }\end{array}$ & $\begin{array}{l}\text { Total quantity } \\
\text { satisfaction } \\
\text { measure }\end{array}$ & $\begin{array}{l}\text { Total quantity } \\
\text { satisfaction } \\
\text { measure }\end{array}$ \\
\hline $\begin{array}{l}\text { Wanping city } \\
\text { block }\end{array}$ & $1-0$ & $0-0$ & $0-0$ & $9-6$ & $4-4$ & $3-3$ \\
\hline
\end{tabular}

satisfaction. The public space use comprehensive satisfaction studies were analyzed and concluded as follows.

6.2.1. Methods for Obtaining Satisfaction Index. Network survey and traditional survey were used to obtain satisfaction index.

6.2.2. Data Filtering. There were more than 2000 pieces of network data of each district. This study selected the data using the six criteria level indicators: $B_{1}$ space location conditions, $\mathrm{B}_{2}$ space traffic environment, $\mathrm{B}_{3}$ space quality, $\mathrm{B}_{4}$ space historical atmosphere, $B_{5}$ space landscape design, and $\mathrm{B}_{6}$ space operation control. Invalid data were deleted (see Table 8).

6.2.3. Data Classification. The data sample was analyzed. The evaluation of the vitality of the public space of the historic district in the microblog content was classified according to the location conditions of $\mathrm{B}_{1}$ space location conditions, the traffic environment of $B_{2}$ space, the quality of $B_{3}$ space, the historical atmosphere of $\mathrm{B}_{4}$ space, the landscape design of $\mathrm{B}_{5}$ space, and the operation control of $\mathrm{B}_{6}$ space (see Tables 9 and 10).

6.2.4. Analysis on the Satisfaction Level. The evaluation of public space was divided into "good," "good," "general," "poor," and "poor." The satisfaction of six evaluation indexes $\mathrm{B}_{1}-\mathrm{B}_{6}$ of public space was calculated (see Table 11).

According to the weight of category $\mathrm{B}$ indicators and $K=$ $[0.214,0.187,0.233,0.126,0.110,0.130]$, the satisfaction of public space in each historic district was calculated. The satisfaction of public space in Wanping Historic Block was found to be 0.2080028 .

6.3. DEA Model. Data based on the index data in Table 11 and DEAP2.1 software were used to calculate comprehensive evaluation of the energy input efficiency of Wanping Historic Blocks. The CCR model of constant scale reward and BCC model of variable scale reward were involved. Table 12 shows Wanping's energy technical efficiency of historic blocks, dynamic pure technical efficiency, and economies of scale. The technical efficiency reflected the current actual output of the 
TABLE 9: Historic district public space satisfaction weight.

\begin{tabular}{lcccccc}
\hline $\begin{array}{l}\text { Decision- } \\
\text { making units }\end{array}$ & $\begin{array}{c}\mathrm{B}_{1} \text { spatial location } \\
\text { condition }\end{array}$ & $\begin{array}{c}\mathrm{B}_{2} \text { space traffic } \\
\text { environment }\end{array}$ & $\begin{array}{c}\mathrm{B}_{3} \text { space } \\
\text { quality }\end{array}$ & $\begin{array}{c}\mathrm{B}_{4} \text { space historical } \\
\text { atmosphere }\end{array}$ & $\begin{array}{c}\mathrm{B}_{5} \text { landscape } \\
\text { space design }\end{array}$ & $\begin{array}{c}\mathrm{B}_{6} \text { space operation } \\
\text { control }\end{array}$ \\
\hline $\begin{array}{l}\text { Wanping city } \\
\text { district }\end{array}$ & 0 & 0 & 0 & 0.7778 & 1 & 0 \\
\hline
\end{tabular}

TABLE 10: Historic district satisfaction weight.

\begin{tabular}{lcccccc}
\hline Weight & 0.214 & 0.187 & 0.233 & 0.126 & 0.11 & 0.13 \\
\hline Wanping city district & 0 & 0 & 0 & 0.0980028 & 0.11 & 0 \\
\hline
\end{tabular}

TABLE 11: Historic district satisfaction levels.

\begin{tabular}{cccccccc}
\hline Number & Description & $\begin{array}{c}\mathrm{B}_{1} \text { spatial } \\
\text { location } \\
\text { condition }\end{array}$ & $\begin{array}{c}\mathrm{B}_{2} \text { space traffic } \\
\text { environment }\end{array}$ & $\begin{array}{c}\mathrm{B}_{3} \text { space } \\
\text { quality }\end{array}$ & $\begin{array}{c}\mathrm{B}_{4} \text { space historical } \\
\text { atmosphere }\end{array}$ & $\begin{array}{c}\mathrm{B}_{5} \text { landscape } \\
\text { space design }\end{array}$ & $\begin{array}{c}\mathrm{B}_{6} \text { space operation } \\
\text { control }\end{array}$ \\
\hline $\mathrm{DMU}_{1}$ & $\begin{array}{c}\text { Wanping city } \\
\text { block }\end{array}$ & 0 & 0 & 0 & 0.7778 & 1 & 0 \\
\hline
\end{tabular}

TABLE 12: The analysis of DEA efficiency.

\begin{tabular}{lcccc}
\hline $\mathrm{Dm} U_{1}$ & Technical efficiency & Pure technical efficiency & Scale efficiency & Scale benefit \\
\hline Wanping city block & 0.658 & 0.739 & 0.891 & Irs \\
\hline
\end{tabular}

TABLE 13: The slack variable analysis of inputs and outputs.

\begin{tabular}{|c|c|c|c|c|c|c|c|}
\hline $\operatorname{Dm} U_{1}$ & $S_{1}^{-}$ & $S_{2}^{-}$ & $S_{3}^{-}$ & $S_{4}^{-}$ & $S_{5}^{-}$ & $S_{6}^{-}$ & $S_{1}^{+}$ \\
\hline $\begin{array}{l}\text { Wanping city } \\
\text { block }\end{array}$ & -0.007 & -0.013 & 0.000 & 0.000 & -0.004 & 0.00 & 0.072 \\
\hline
\end{tabular}

decision-making unit and has reached the proportion of the maximum possible output. When technical efficiency $>1$, the public space of the historical block was shown as the technically efficient space. Otherwise, it was a technically invalid space. Pure technical efficiency refers to the impact from the utilization of input resources on comprehensive technical efficiency. Scale efficiency refers to whether the input and output reach the best state. If scale efficiency $>1$, the input and output are not optimized.

Table 12 shows that both pure technical efficiency and scale efficiency of Wanping historic district are lower than average. They were in the range of non-DEA effective incremental scale efficiency (irs), and a deep activation restoration for its vitality was needed. In order to accurately evaluate the spatial activation efficiency of Wanping Historic Blocks, the input-output relaxation variables of historical blocks were analyzed (see Table 13).

\subsection{Evaluation Index Verification}

6.4.1. Verification of Vitality of Historical Buildings (Structures). Historical buildings (structures) are critical elements of public space and presents the enclosed interface of historic districts [27]. They also play a very important role in the six indicators. In order to better hold international and national activities for commemoration and tourism purposes, there was an urgent need for the Wanping historic district to show its historical and cultural resources. In addition, systematic publicity and overall planning are needed to be undertaken. Moreover, the Lugouqiao area was considered an important catalyst carrier in the city; thus, scenic spots and historic sites were needed. Protection and maintenance were highly appreciated in the activation of Wanping historic district (see Figure 2). In order to continue the traditional street pattern and carefully protect the scenic spots and historic sites, this study used the activation and promotion strategies for the historical buildings in the Wanping historic district (see Table 14).

In order to better improve the maintenance of the historical resources in Wanping historic district, the AHP method was used to calculate the evaluation score of the importance of each historical building (see Table 15). There were 70 items in the evaluation. The average score was 1.45 , with the lowest score 0.47 and the highest score 2.31. It was found that the color changed from dark to light and those with a score higher than 2 were the most important resources for public space or historical buildings. They also included the historical sites for commemorating the victory of the Anti-Japanese War and the patriotic activity base for Anti-Japanese Red Culture. The comprehensive planning of Yongding River Green Ecological Development Zone had a great impact on the landscape environment as well.

Sites with historic interest and scenic beauty were the crucial areas in the key competitiveness and sustainable development of 

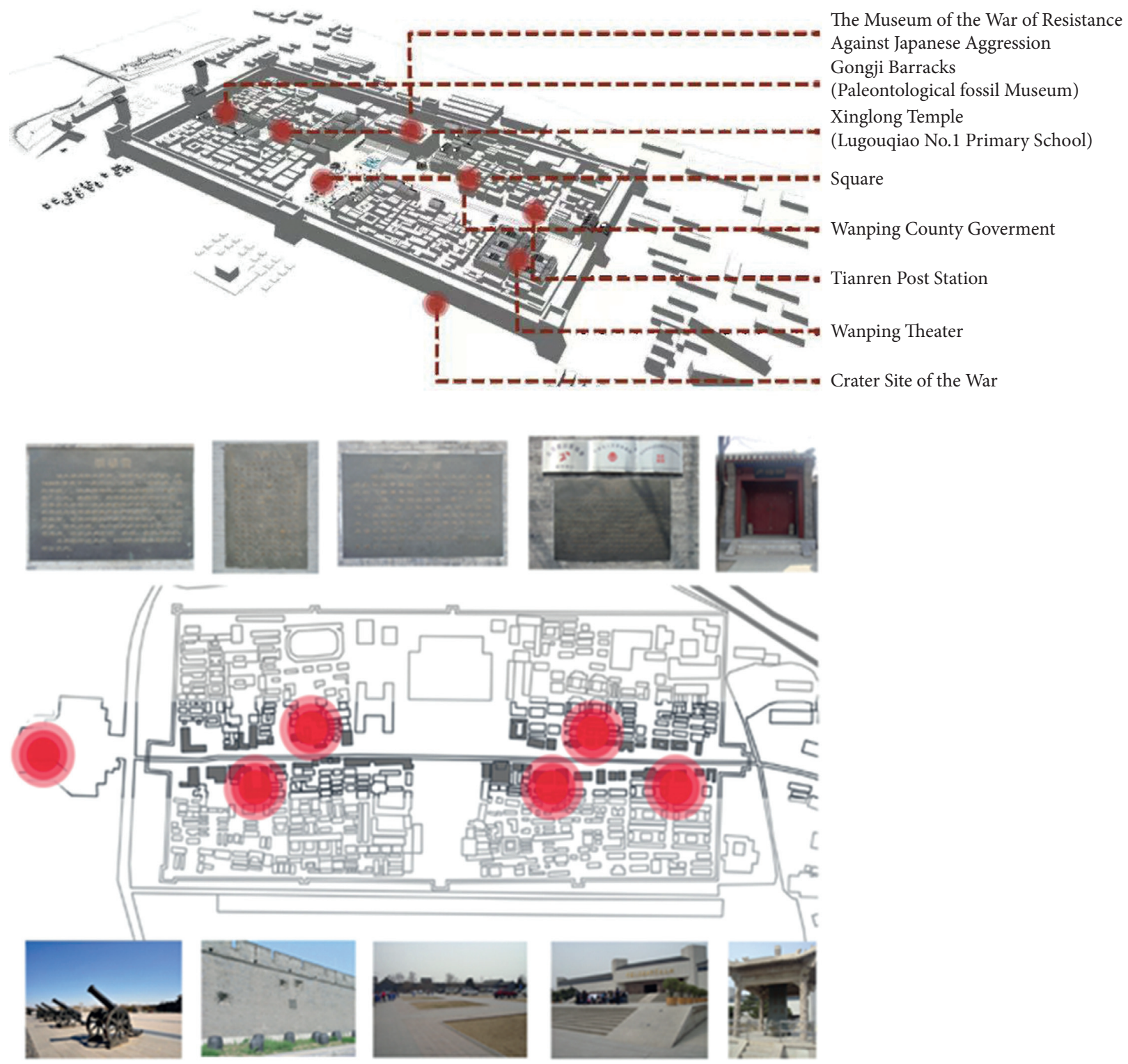

FIgURE 2: Historical resource distribution map of Wanping historic district.

Wanping historic district [28]. All renewal and development should be conducted based on its activation and upgrading. Therefore, it was essential to develop a step-by-step model rather than a "put down and rebuild" model. Moreover, a mixed procedure to separate space was needed rather than simply renovating the building or blindly redeveloping the area. Additionally, these strategies and procedures were needed to be sustainable for future innovative development (see Figure 3).

6.4.2. Historical Space Value. The historical values of $\mathrm{B}_{4}$ space in the criterion layer of public space activation and promotion included the fusion degree of $\mathrm{C}_{26}$ ancient and modern style, the reservation degree of $\mathrm{C}_{28}$ historical buildings and historical environment, and the identification degree of $\mathrm{C}_{29}$ historical texture. In $\mathrm{B} 4$, the index weight of $\mathrm{C}_{28}$ was 0.461 , followed by $\mathrm{C}_{26}(0.335)$. The index weight of $\mathrm{C}_{29}$ was 0.203 , which was low. This study investigated the fusion degree of $\mathrm{C}_{26}$ ancient and modern style and the reservation degree of $\mathrm{C}_{28}$ historical buildings and historical environment in Wanping historic district (see Figure 4). These two parts provided significant support for the activation and promotion of the Wanping historic district. Nevertheless, limitations still exist, and the activation and promotion of the Wanping historic district needed to be improved.

Historical Resources Needed to Be Further Developed. It was found that although there were sufficient historical and cultural resources in and around Wanping historic district, the excavation and utilization levels were low. The overall space texture of the city was good, but the overall style and features were not well protected. For example, many privately built houses destroyed the courtyard pattern.

Historical Building Resources Needed to Be Activated. There were many significant nodes in Wanping historic district, which were patriotic activity base, public space, landscape 
TABLE 14: Wanping district historical building activation promotion model.

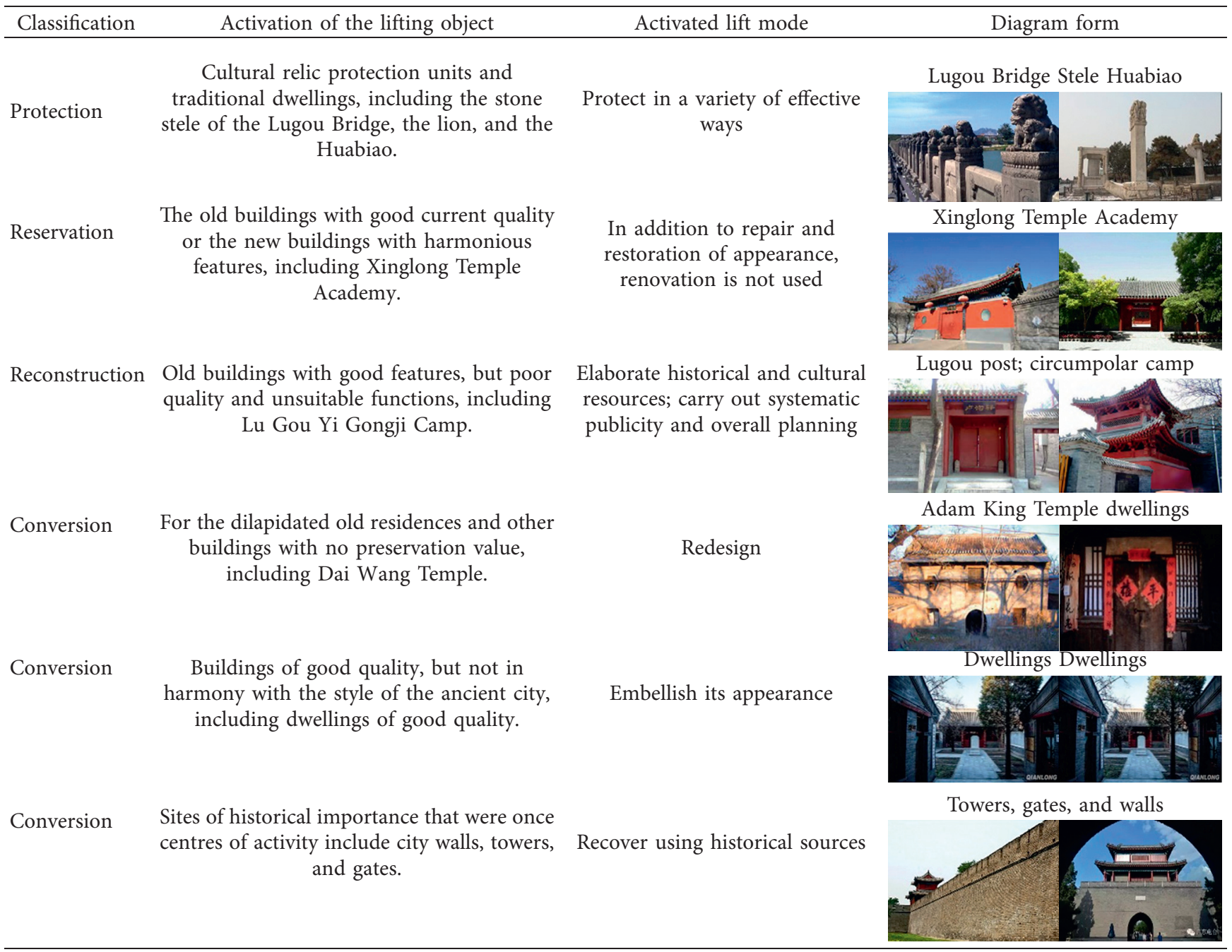

environment, places of interest, city walls, and gates. The utilization rate of these resources was low, and the Daiwang Temple in Xiaoyue island needed to be repaired (see Table 16).

\section{Discussion and Suggestions}

In order to further verify the feasibility of the multisource data superposition and AHP/DEA model, this paper used Wanping historic district in Fengtai District of Beijing as a case study to investigate the multisource data superposition model. In this model, the evaluation index of public space vitality was selected and the evaluation results of Wanping historic district samples with the AHP and DEA model were also calculated. A comparative study was undertaken (see Figure 5):

(1) The results of multisource data superposition were consistent with the vitality elements of public space in Wanping historic district. This method can be seen as feasible, but there are still some limitations. It is suggested that the selection of big data be more refined, and the selection of vitality evaluation index needs to be further studied.
(2) The results of AHP and DEA model calculation showed the criterion layer $B_{5}$ in the index system of Wanping historic district public space activation promotion represented the space landscape design, including the evaluation index layer $\mathrm{C}_{33}$ plant color [17], $\mathrm{C}_{34}$ water landscape design, $\mathrm{C}_{36}$ shading rate, $\mathrm{C}_{39}$ lighting facilities [29], and $\mathrm{C}_{40}$ recreational facilities $[30,31]$. In the space landscape design $\left(B_{5}\right)$ of Wanping historic district, the index weight of $\mathrm{C}_{33}$ was 0.413 (high), followed by the index weight represented by $\mathrm{C}_{40}(0.225)$. The lowest index weight was represented by $\mathrm{C}_{36}(0.075)$. They were consistent with the current situation of public space in Wanping historic district. The three-dimensional landscape was added to the inner street of Wanping historic district. The color levels were added to the plants and trees, and layers were also added to shrubs and grasses, forming "a green space." However, the landscape of the inner street of Wanping historic district needed to be improved. For example, the environmental quality and protection of cultural values and properties along Beijing-Shijiazhuang 
TABLE 15: Average score summary of historical and cultural resource evaluation results.

\begin{tabular}{|c|c|c|c|c|c|c|}
\hline & & Germplasm & $\begin{array}{c}\text { Patriotic } \\
\text { campaigns } \\
\text { base }\end{array}$ & $\begin{array}{l}\text { Street } \\
\text { square }\end{array}$ & $\begin{array}{l}\text { Landscape } \\
\text { environment }\end{array}$ & $\begin{array}{c}\text { Places } \\
\text { of } \\
\text { interest }\end{array}$ \\
\hline \multirow{14}{*}{$\begin{array}{l}\text { Importance } \\
\text { evaluation score }\end{array}$} & \multirow{6}{*}{$\begin{array}{l}\text { Policy } \\
\text { resource }\end{array}$} & $\begin{array}{c}\text { The policy of commemorating the victory of } \\
\text { the Anti-Japanese War }\end{array}$ & 2.03 & 1.29 & 0.93 & 1.65 \\
\hline & & Wanping City Renewal Policy & 1.96 & 1.81 & 1.54 & 1.90 \\
\hline & & Fengtai District 13th Five-Year Plan & 1.56 & 1.43 & 1.62 & 1.71 \\
\hline & & $\begin{array}{l}\text { Yongding River green ecological } \\
\text { development zone comprehensive planning }\end{array}$ & 1.46 & 1.54 & 2.16 & 1.35 \\
\hline & & Construction of rail transit policy & 1.51 & 1.69 & 1.63 & 1.46 \\
\hline & & Improve slow travel system policy & 1.54 & 1.90 & 1.97 & 1.62 \\
\hline & \multirow{4}{*}{$\begin{array}{l}\text { Historical } \\
\text { resources }\end{array}$} & South of the portal & 1.16 & 1.35 & 1.59 & 1.56 \\
\hline & & Historical events of the Anti-Japanese War & 2.10 & 1.37 & 0.88 & 1.72 \\
\hline & & Historical legends & 1.40 & 1.10 & 0.85 & 1.90 \\
\hline & & Anti-Japanese Red Culture & 2.00 & 1.26 & 0.87 & 1.69 \\
\hline & \multirow{4}{*}{$\begin{array}{l}\text { Cultural } \\
\text { resources }\end{array}$} & Ancient Architectural Culture & 1.56 & 1.47 & 1.54 & 1.99 \\
\hline & & Carving Art and Culture & 1.21 & 1.21 & 1.31 & 1.60 \\
\hline & & Leisure Tourism Culture & 1.59 & 1.71 & 1.75 & 1.94 \\
\hline & & Mid-Autumn Folk Culture & 0.97 & 1.18 & 1.41 & 1.50 \\
\hline
\end{tabular}
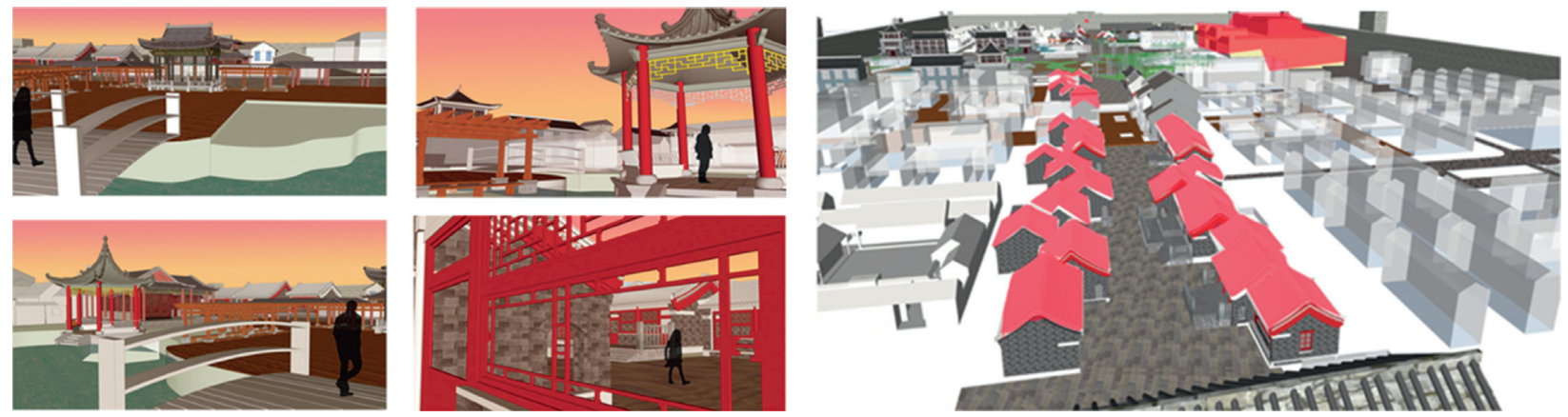

FIGURE 3: Wanping historic district activation restoration effect.
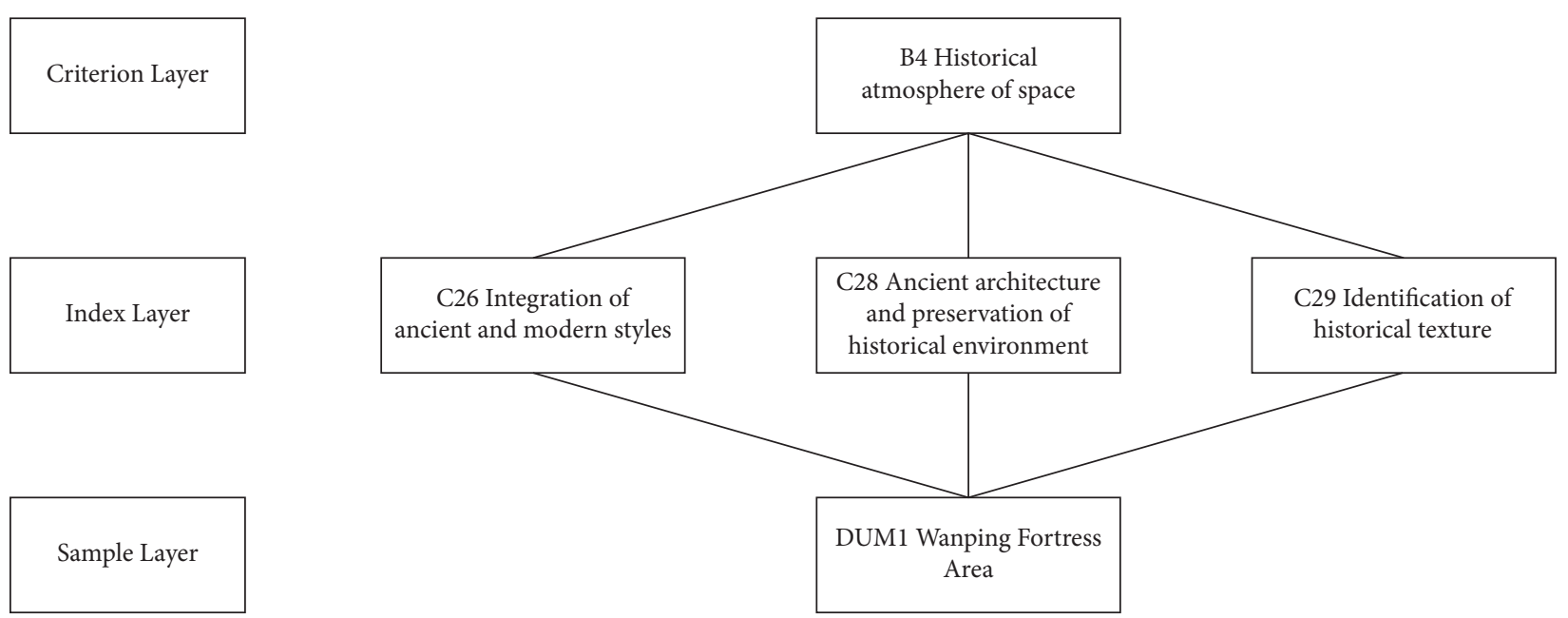

Figure 4: The hierarchy structure model of historical atmosphere.

Expressway and the surrounding roads of Wanping historic district needed to improve as they were the main access to Wanping historic district. Moreover, the coastal landscape of Xiaoyue lake also needed to be improved. The data results calculated by the AHP and DEA model were found slightly different from 
TABLE 16: Historical building resources of Wanping historic district.

\begin{tabular}{|c|c|}
\hline Catalyst carrier & Content \\
\hline Patriotic activity base & $\begin{array}{l}\text { Anti-Japanese War Memorial Hall } \\
\text { Anti-Japanese War Sculpture Garden } \\
\text { The Site of the July 7th Incident Crater }\end{array}$ \\
\hline Street square & $\begin{array}{c}\text { Peace (Lion Dance) Square } \\
\text { East and West Square of Lugou Bridge } \\
\text { The City Street }\end{array}$ \\
\hline Landscape environment & $\begin{array}{c}\text { Aria Island } \\
\text { Yongding River and riverside green belt } \\
\text { The landscape along Beijing and Shi }\end{array}$ \\
\hline Places of interest & $\begin{array}{c}\text { Circumpolar camp } \\
\text { Lugou post } \\
\text { Arsenal } \\
\text { Lugou Bridge } \\
\text { Wan ping county government } \\
\text { Adam King Temple } \\
\text { Xinglong Temple Academy } \\
\text { Towers, gates, and walls } \\
\text { Stone lions and stone stele }\end{array}$ \\
\hline
\end{tabular}

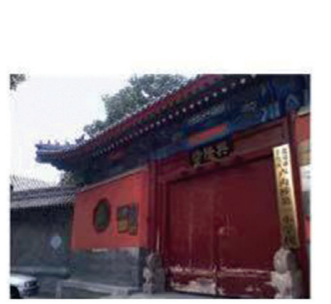

Ancient city culture

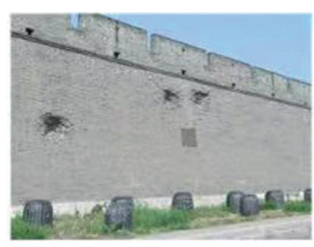

Traces of war

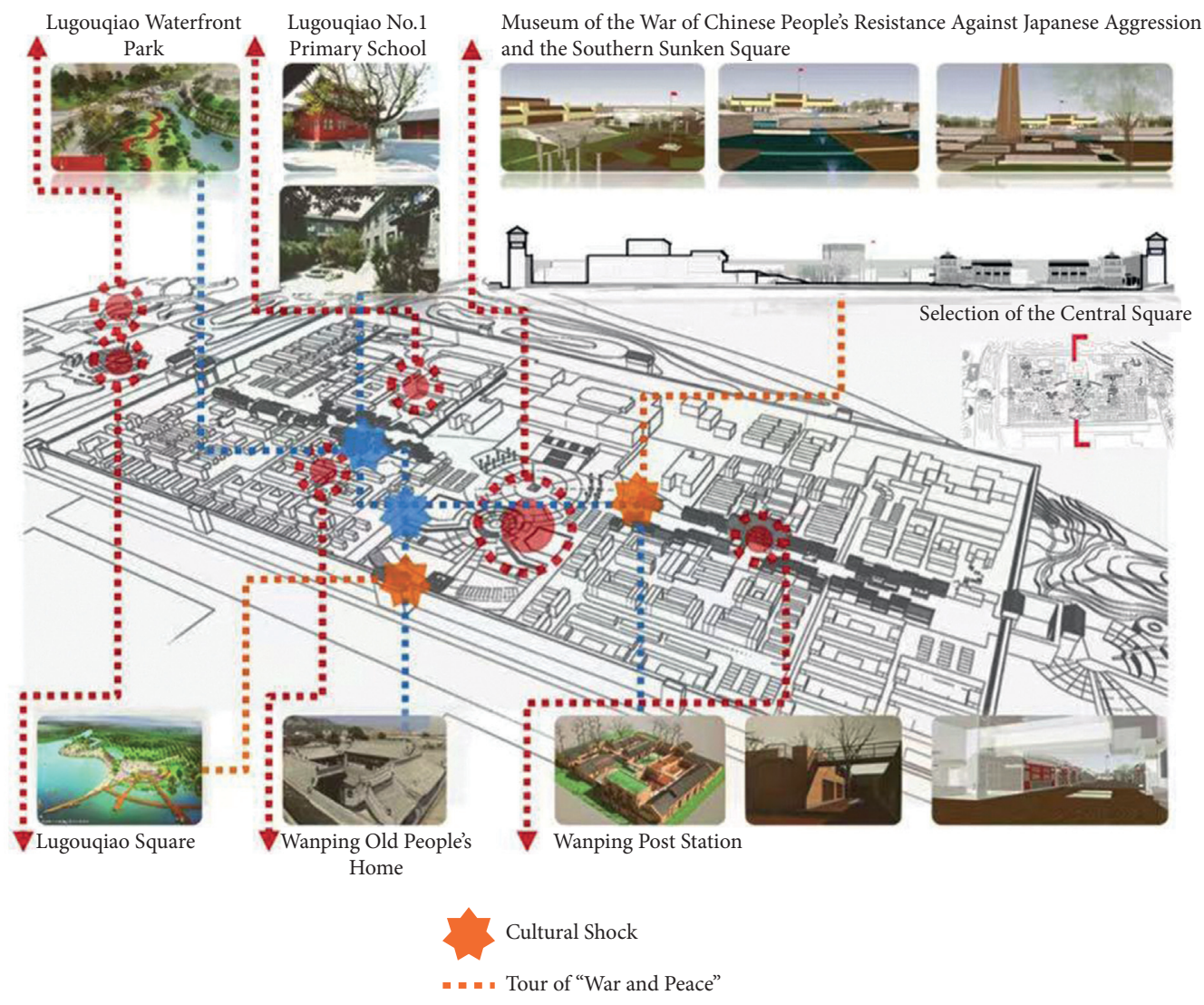

Cultural Integration

Tour of ancient cities

- " - in ming and Qing Dynasties

FIgURE 5: Wanping historic district landscape levels.

the reality. Thus, further research is needed to study the coupling of AHP and DEA models [32].

(3) Using the DEA model, the vitality efficiency of Wanping Historic Blocks was evaluated. It was found that Wanping Historic Blocks had redundant input at all index levels, resulting in waste of resources and low vitality of public space. Protection and control of space resources were needed to promote the activation of block space and improve the vitality efficiency of blocks. 
(4) This research also found one unique case: the operation and management of $\mathrm{B}_{6}$ space. The operation and control of $\mathrm{B}_{6}$ space were the key to maintain the long-term vitality of public space. The research was conducted from five aspects. Moreover, the density of service format was the ratio of individual service format to all the formats. The organization and management were measured by using the policy terms. It was found that the facilities were at standard levels; the environment was clean; and the space facilities were maintained well. There was only a sole service industry in Wanping historic district. In terms of organization and management, there was still a certain gap between market management and community management, and the survey evaluation results were both 3. However, the results of the AHP and DEA models showed the satisfaction ratio is 0 ; that is, the satisfaction level was high.

Further studies should be done by transforming qualitative elements into quantitative data in the operation and management of the B6 space.

\section{Conclusion}

Attention should be paid on how to enhance the vitality of the public space in historical blocks during the urban development. In this paper, the multisource data superposition method was used to obtain the vitality efficiency index of public space. The AHP and DEA model were also used to construct the evaluation system of vitality efficiency of public space $[33,34]$; the existing rules of the internal historical and cultural connection between various elements of public space were established; and the Wanping Historic Block was used as a case study $[35,36]$.

This paper made the following important contributions.

(1) The multisource data superposition method was used to develop the evaluation index of the activation and promotion of the public space in historic district. In this paper, three kinds of data, namely, literature review data and traditional research data, were used to construct an index system for the evaluation of public space activation improvement. Qualitative and quantitative indicators were both used to make our research more scientific, rigorous, and innovative.

(2) Vitality efficiency was used to measure the spatial vitality of historic blocks. This economics model for researching public space helped the management of economies of scale. It could be applied to the public space in the study of energy efficiency. The energy efficiency DEA model was used to calculate the energy efficiency of Wanping historic district public space and refine space resource into upgrading the dynamic improvement of the space redundancy.

(3) The evaluation model of the public space vitality promotion in the historic district was established based on
AHP and DEA models. The evaluation system of public space vitality efficiency was constructed, including "extracting index factors, building index system, building evaluation model, realizing vitality promotion evaluation and vitality promotion verification." It was found the standardization of vitality promotion evaluation should be avoided, while the character and differentiation of public space vitality should be ignored.

(4) Finally, the case study of Wanping historic district was conducted to verify the usefulness of AHP and DEA models in promoting the vitality of public space in historic districts. It is worth noting that the AHP method lacks more subjective weight than Produces Rank Reversal. Therefore, exploring the application of multistandard decision discount method [37] and interval preference relationship [38] in the historic district space should be used to evaluate the vitality of historic districts more objectively and scientifically in future studies.

In summary, this paper adopted the DEA model of dimensionless characteristics, which is consistent with the characteristics of historical block energy efficiency. It can be directly applied to energy efficiency measurement of historic blocks, without setting from special functions being defined. Both qualitative and quantitative indicators were used to ensure the accuracy of the calculation process and dimensionless processing. In addition, combining AHP and DEA models, this paper evaluated the activation efficiency of historic blocks public space and the complexity of the dynamic evaluation corresponds to the historic district and compensates each other. It helped to control the uncertainty and fuzziness in the process of AHP analysis. This paper thus contributed to establishing a more scientific, objective, accurate, and targeted evaluation method for vitality improvement [39] of the historical block protection, with a further goal to evaluating and restoring traditional villages in public space of industrial heritage blocks nationwide and worldwide.

\section{Data Availability}

All the data are included within this manuscript.

\section{Consent}

Not applicable.

\section{Conflicts of Interest}

The authors declare no conflicts of interest.

\section{Acknowledgments}

This study was supported by the National Natural Science Foundation of China (Grant nos. 51478007 and 51978005) and Beijing Municipal Education Commission Science and Technology General Project (Grant no. KM201110005025). 


\section{References}

[1] Y.-S. Ruan, "Protection and planning of historic district," Urban Planning Forum, vol. 46, no. 02, pp. 47+50-80, 2000, in Chinese.

[2] Y. Ruan and W. Wang Jinghui, Protection Theory and Planning of Historical and Cultural City, Tongji University Press, Shanghai, China, 1999.

[3] S. Thiesmore, The Renaissance of Urban Historic Districts, China Construction Industry Press, China, 2006.

[4] D. Huang, Q. Luo, and J. Wang, "A study on the Revitalization Strategy of Historic District-a case study of the surrounding area of Yuyao factory," Architecture \& Culture, vol. 15, no. 02, pp. 143-144, 2018, in Chinese.

[5] X. Zhou, "Revitalization Strategy of Historical and Cultural Blocks under Shared Development: A Case Study of Shichahai Historical and Cultural Block in Beijing," in Proceedings of the 2018 China Urban Planning Annual Conference (02 Urban Renewal), p. 10China Society of urban planning, Hangzhou Municipal People's Government. Sharing and Quality, Hangzhou, China, November 2018.

[6] F. Wu, "Research on Public Space Quality Evaluation of Beijing Historic District Based on Network Public Opinion Analysis -Taking Nanluoguxiang Block as an Example," in Proceedings of the Proceedings of 2017 China Urban Planning Annual Meeting (05 Application of New Urban Planning Technologies), p. 18, China Society of urban planning, Dongguan Municipal People's Government. Sustainable Development and Rational Planning:, London, UK, May 2017.

[7] X. Li, Research on Traffic and Municipal Engineering Technology in Historical Block Protection, Southeast University Press, Nanjing, China, 2012.

[8] B. Zhang, Protection and Renewal of Historical and Cultural Blocks, Intellectual property press, Nanjing, China, 2013.

[9] Y.-T. Wang and Y.-F. Wei, "Research on the reconstruction of public spaces in historic block of cities by combining with space syntax and PSPL research methodtaking the block of maliandao as an example," Research on Heritages and Preservation, vol. 3, no. 04, pp. 50-55, 2018, in Chinese.

[10] Y.-J. Ren, "Vitality of old town public space from revival of cultural life-a case study of small and medium-sized cities," Journal of Henan University of Urban Construction, vol. 25, no. 02, pp. 7-11, 2016, in Chinese.

[11] X.-H. Hao, Y. Long, M. Shi, and P. Wang, "Street vibrancy of beijing: measurement, impact factors and design implication," Shanghai Urban Planning Review, vol. 26, no. 03, pp. 37-45, 2016, in Chinese.

[12] Y. Long and Y. Zhou, "Quantitative evaluation on street vibrancy and its impact factors: a case study of chengdu," New Architecture, vol. 24, no. 01, pp. 52-57, 2016, in Chinese.

[13] M. Xu and C. C. Wang, "Research on the evaluation system of historical and cultural district renewal based on multi-source data -- a case study of historical and cultural district in guangdong province," Urban Development Studies, vol. 26, no. 2, pp. 74-83, 2019, in Chinese.

[14] Y. Ruan and P. Ju, Oral Record of Ruan Yisan's Road to Protect the City, East China Normal University Press, Shanghai, China, 2015.

[15] S. . -R. Jiang, X. Tan, L. Shi, and Z. Ma, “Analysis of industrial air pollution emission efficiency of Beijing Tianjin Hebei air pollution transmission channel cities based on Three-stage DEA method," Journal of Arid Land Resources \& Environment, vol. 33, no. 06, pp. 141-149, 2019, in Chinese.
[16] P. Hu, X. Bai, and Z.-L. Wang, "Analysis on the application of AHP-DEA in hospital financial risk assessment," Chinese Health Economics, vol. 37, no. 12, pp. 104-107, 2018, in Chinese.

[17] S.-R. Guo and D.-H. Yang, "Preservation and renewal methods of "+ pocket park" mode of historic district -- a case study of nanhexia historical and cultural district in yangzhou," Huazhong Architecture, vol. 36, no. 10, pp. 122-125, 2018, in Chinese.

[18] Z. Li and J.-S. Lin, "Spatial analysis method of urban environmental traffic capacity," Journal of Southeast University: Natural Science Edition, vol. 39, no. 6, p. 5, 2009, in Chinese.

[19] C. Bai, "Public Space and Vitality Building: A Study Based on the Public Space of Two Walking Historic Blocks," in Proceedings of the 2018 China urban planning annual conference (07 urban design), China Society of urban planning, Hangzhou Municipal People's government. Sharing and Quality, pp. 1118-1127, Hangzhou, China, November 2018.

[20] X. Zhou, "Revitalization Strategy of Historical and Cultural Blocks under Shared Development: A Case Study of Shichahai Historical and Cultural Block in Beijing," in Proceedings of the 2018 China Urban Planning Annual Conference (02 Urban Renewal), China Society of urban planning, Hangzhou $\mathrm{Mu}-$ nicipal People's Government. Sharing and Quality, pp. 424433, Hangzhou, China, November 2018.

[21] L. Dong, "The landscape evaluation system of public space in historic district -a case of shichahai historic district," Architecture \& Culture, vol. 16, no. 03, pp. 129-130, 2018, in Chinese.

[22] M. Liu, "Landscape design of public communication space in," Urban Historic District Art and Design, vol. 2, no. 3, pp. 42-44, 2018, in Chinese.

[23] M. Zhang, Managing Urban Historic District, Doctoral Dissertation, Tongji University, Shanghai, China, 2007.

[24] J. Yang, Urban Renewal and Protection, Southeast University Press, Nanjing, China, 1999.

[25] F. Wu, "Research on the transformation of public space of zhonggulou block in beijing based on cultural heritage," in Proceedings of the 2014 (9th) Urban Development and Planning Conference - Protection and Renewal of S15 Historical and Cultural Blocks, pp. 161-166, China Society for Urban Science Research, Tianjin Binhai New Area People's Government, Taipei, Taiwan, April 2014.

[26] F. Wu, "Research on the transformation of public space in historical blocks based on cultural heritage: a case study of Zhonggulou block in Beijing," in Proceedings of the 2014 China Urban Planning Annual Meeting (06 Urban Design and Detailed Planning), pp. 901-914, China Society of Urban Planning. Urban and Rural Governance and Planning Reform, Taipei, Taiwan, April 2014.

[27] L.-C. Bian and Y. Shi, "On the overall protection of Beijing historic district from the perspective of society space," Shanghai Urban Planning Review, vol. 27, no. 06, pp. 1-7, 2017, in Chinese.

[28] N. Su, "Strategy research on localization inheritance and renewal of traditional historical blocks public space environmenttake seven lane three lane in fuzhou as an example," Architecture \& Culture, vol. 15, no. 2, pp. 224-225, 2017, in Chinese.

[29] Y. Pei, Q. H. Wu, Y. Q. Tang, T. T. Li, and Y. Long, “Analysis of street vitality and influencing factors at night in the second ring road of Beijing based on spatial data," Urbanism and Architecture, vol. 15, no. 9, pp. 111-116, 2018, in Chinese. 
[30] Y. Lin and J. Dong, "A research on the planning strategy for the child-friendly public space of urban block," Journal of Xi'an University of Architecture and Technology, vol. 37, no. 5, pp. 24-31, 2018, in Chinese.

[31] S. Liu, Z.-Y. Huang, and M.-F. Yao, "Research on the analysis of pubic space in the spontaneously formed university city based on the students' class behavioral activity-taking shigu road blocks in xiamen as an example," Chinese Times and Overseas Architecture, vol. 24, no. 09, pp. 113-117, 2018, in Chinese.

[32] Y. Luo, Index Selection and Environmental Efficiency Evaluation Based on DEA Method, Doctoral dissertation, University of science and technology of China, Hefei, China, 2012.

[33] A. P. Gou and J.-B. S. D. Wang, "Method based street space vitality evaluation," Planners, vol. 10, pp. 102-106, 2011, in Chinese.

[34] T. Lin and J.-F. Ning, "Study on allocation efficiency of carbon emission permit in EUETS based on ZSG-DEA model," The Journal Of Quantitative and Technical Economics, vol. 03, pp. 36-50, 2011, in Chinese.

[35] W. M. Zhao, W.-Y. Peng, and Y. Huang, "Research on the conservation and regeneration of historical city quarter based on social network reestablishment-a case study of sandaoguai historical quarter in changshou district chongqing," Planners, vol. 02, pp. 9-13, 2008, in Chinese.

[36] H.-P. Zhou and F. Chen, "Evaluation of Urban Public Transport Efficiency Based on DEA and SFA," Journal Of Changsha University, vol. 22, no. 05, pp. 79-82, 2008, in Chinese.

[37] F. Smarabdache, "A-Discounting method for multi-criteria decision making (a-DMCDM)," in Proceedings of the 2010 13th Conference on Information Fusion (FUSION), vol. 21, pp. 1-7, Review of the Air Force Academy, Edinburgh, UK, July 2010.

[38] S. P. Wan, H. W. Yuan, and J. Y. Dong, "Decision making with incomplete interval multiplicative preference relations based on stochastic program and interval category," Information Sciences, vol. 570, no. 1, 2021.

[39] L. Zheng, Research on the Dynamic Protection of Historic Districts, Doctoral Dissertation, Tianjin University, Tianjin, China, 2004. 